\title{
A Two-year Review of Admissions to the Intensive Care Unit of the Georgetown Public Hospital Corporation, Guyana
}

\author{
O Henry, AO Amata
}

\begin{abstract}
Objective: To review the patterns of admissions, characteristics and clinical outcomes of the patients admitted to the seven-bed multidisciplinary general Intensive Care Unit (ICU) of the Georgetown Public Hospital Corporation (GPHC), Guyana.

Methods: This was a retrospective study of all the patients admitted to the ICU between January 2008 and December, 2009. The study was conducted mainly by chart reviews and the collected data were stored and analysed using Microsoft Excel programme. Results: A total of 734 patients were admitted to the unit during the study period. Males comprised $56.5 \%$ and most of the admissions were from the operating rooms (38\%). The mean age of the patients was 36 years, of this two-thirds (67\%) of the patients were below 41 years. The average ICU length of stay (LOS) was 5.46 days with the survivors having a longer LOS than the non-survivors. Trauma was the largest diagnosis (24\%) of the patients' admission, and mortality was highest among the medical and paediatric patients. The ICU mortality rate was $48 \%$.

Conclusion: Our ICU mortality was relatively high and many of the deaths were potentially preventable by simple public health interventions like immunization, vehicular accident reduction strategies, suicide prevention strategies, better sanitation, greater availability of primary healthcare, prompt basic emergency services, and regular availability of essential laboratory services and pharmaceutical supplies.
\end{abstract}

Keywords: Critical care, Guyana, intensive care, intensive care unit, review

\section{Una Revisión de dos Años de Ingresos en la Unidad de Cuidados Intensivos de la Corporación del Hospital Público de Georgetown, Guyana}

\author{
O Henry, AO Amata
}

\begin{abstract}
RESUMEN
Objetivo: Revisar los patrones de ingresos, características y resultados clínicos de los pacientes ingresados en la unidad multidisciplinaria de cuidados intensivos de siete camas (UCI) de la Corporación del Hospital Público de Georgetown (GPHC), Guyana.

Métodos: Este fue un estudio retrospectivo de todos los pacientes ingresados a la UCI entre enero de 2008 y diciembre de 2009. El estudio se realizó principalmente mediante revisión de las historias clínicas, y los datos recopilados se almacenaron y analizaron usando el programa Microsoft Excel.
\end{abstract}

From: Department of Anaesthesia and Intensive Care, Georgetown Public Hospital Corporation, East and Middle Streets, Georgetown, Guyana.
Correspondence: Dr AO Amata, Department of Anaesthesia and Intensive Care, Georgetown Public Hospital Corporation, East and Middle Streets, Georgetown, Guyana. Email: aoamata@yahoo.com 
Resultados: Un total de 734 pacientes fueron ingresados a la unidad durante el periodo de estudio. Los varones comprendieron el $56.5 \%$ y la mayor parte de los ingresos provenían de las salas de operación (38\%). La edad promedio de los pacientes fue 36 años, y dos tercios (67\%) de los pacientes tenían menos de 41 años. La duración promedio de la estancia en la UCI fue de 5.46 días, teniendo los supervivientes un tiempo más largo que los no sobrevivientes. El trauma fue el diagnóstico más general (24\%) para el ingreso de pacientes y la mortalidad fue mayor entre los pacientes de las áreas de medicina y pediatría. La tasa de mortalidad de la UCI fue de $48 \%$.

Conclusión: Nuestra mortalidad en la UCI fue relativamente alta y muchas de las muertes fueron potencialmente prevenibles por intervenciones simples de salud pública, tales como inmunización, estrategias para la reducción de accidentes vehiculares, estrategias de prevención de suicidios, mejor saneamiento, mayor disponibilidad de atención a la salud primaria, servicios básicos rápidos de emergencia, así como disponibilidad regular de servicios de laboratorio esenciales y suministros farmacéuticos.

Palabras clave: Atención crítica, Guyana, cuidados intensivos, unidad de cuidados intensivos, revisión

West Indian Med J 2017; 66 (6): 629

\section{INTRODUCTION}

The intensive care unit (ICU) is now an integral part of most modern hospitals. It is a specialized unit equipped to provide advanced care to critically ill patients. The Georgetown Public Hospital Corporation (GPHC) ICU, opened in May 1996, under the Department of Anaesthesia, is a multidisciplinary unit catering for patients from infancy to adulthood. It is a seven-bed unit with two of these beds in a side-room. The ICU consultant coverage is provided by the Anaesthesia consultants and a full-time intensivist. There is a consultant on call and a general medical officer or resident physician physically present 24 hours a day in the ICU. It is a semi-open unit, where patients are co-managed by the ICU team and the primary admitting team. Nursing care is currently provided by a mix of trained critical care nurses, staff nurses and nursing assistants.

Georgetown Public Hospital Corporation is the apex national referral and tertiary university-affiliated hospital in the country with 500 acute care beds. Patients admissions to the ICU are not only from within the hospital and the environs of Georgetown but also by referrals from all over the country by air, sea or road. Healthcare is free of charge to patients in all the public health facilities in Guyana which is a tropical low-income developing country located in the Northern coast in South America. It is sparsely populated with about 750000 inhabitants spread over an area of $215000 \mathrm{~km}^{2}$ and is about the size of the United Kingdom (1).
Intensive care is expensive and consumes a disproportionate amount of the hospital's budget (2). To make it cost-effective and efficient, the service has to be tailored to the needs and resources of the catchment area. This requires systematic auditing of the service. There is significant literature on reviews, audits and analysis of ICUs (2-5) but these have been mainly done in the Western developed world where resources and casemix are quite different, thus, such findings may not be wholly extrapolatable to our local situation. Published information on intensive care in Guyana is lacking. The purpose of this study therefore, was to review the pattern of admissions, characteristics and outcomes of the patients admitted to the ICU.

\section{METHODS}

This was a retrospective study of all the admissions to the ICU of GPHC between January 1, 2008 and December 31, 2009; and it was conducted using patients' charts at the GPHC Records Department, with the ICU database and nurses' report book used for triangulation. The inclusion criterion for selection was that all the patients admitted to the ICU completed charts must be available for use. The patients with missing or grossly incomplete charts were excluded from the study.

The patients' demographic and clinical data were retrieved. Their demographic information included: age, gender, ethnicity, and source and duration of admission. Their clinical data included: their primary diagnosis, 
primary specialty, indication for admission and the need for mechanical ventilation and patient outcome (death or discharge). The severity of illness score was not included as this was not routinely done during the study period. In ICU studies, patients are classified in different ways such as according to their diagnosis, disease classification, age, primary specialty on admission, etc. Each has its limitations. We chose to use the patients' primary specialty on admission for simplicity but included trauma as a group on its own because of its often multidisciplinary nature. Paediatric group included only paediatric medical cases as paediatric surgical and trauma cases were included with the surgery or trauma groups and the paediatric age group was considered as patients under the age of 13 years.

Microsoft Excel was used to analyse the data collected. Tables and graphs were generated using this programme. Descriptive statistics were computed for the variables (age, gender, referring specialty, diagnosis, treatment outcome and length of stay). The results are presented as frequencies and percentages in tables and graphs. A $p$-value $<0.05$ was considered significant.

The approval for this study was granted by the institution via the Office of the Director of Medical and Professional Services.

\section{RESULTS}

During the two-year study period, there were a total of 734 admissions to the ICU. Ten charts could not be located. Of the 724 records analysed, there were 347 deaths and 377 discharges. The mortality rate for the period of study was $48 \%$. The bed occupancy and bed turnover for the period of study were $73.3 \%$ and $2.3 \%$, respectively. The males comprised the majority with $56.5 \%$. The mean age of the patients was 36.1 years and that of the modal group was $21-40$ year (30.9\%) [Table 1].

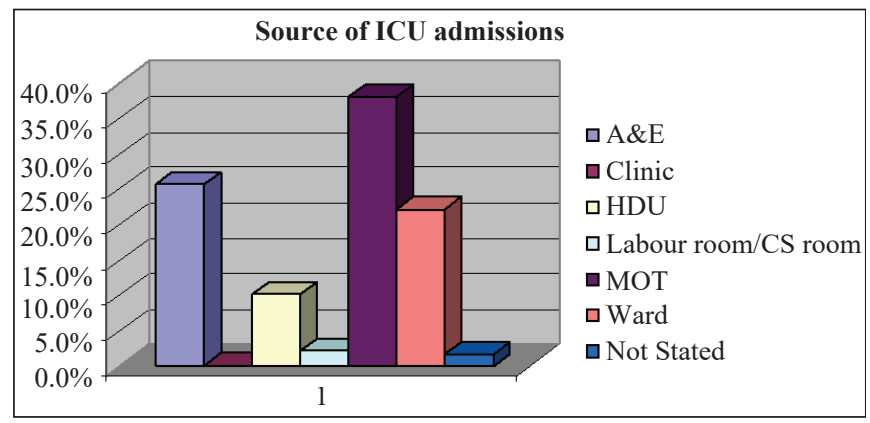

Fig. 1: Sources of the intensive care unit admission.

A\&E: Accident and Emergency Department; HDU: high dependency units; MOT: main operating theatre
The majority (38\%) of the patients admitted to the ICU were from the main operating theatre. The Accident and Emergency Department (A\&E) accounted for the second largest proportion of the admissions with $25.7 \%$ and the wards and high dependency units (HDU) followed with $22 \%$ and $10 \%$, respectively (1.)

The most common indications for admission were medical, surgical and trauma, each accounting for $24 \%$ of the admissions. Obstetric and gynaecologic indications accounted for $16 \%$ and paediatric indications $13 \%$ (Fig. 2.)

Table 1: The demographics of the study sample.

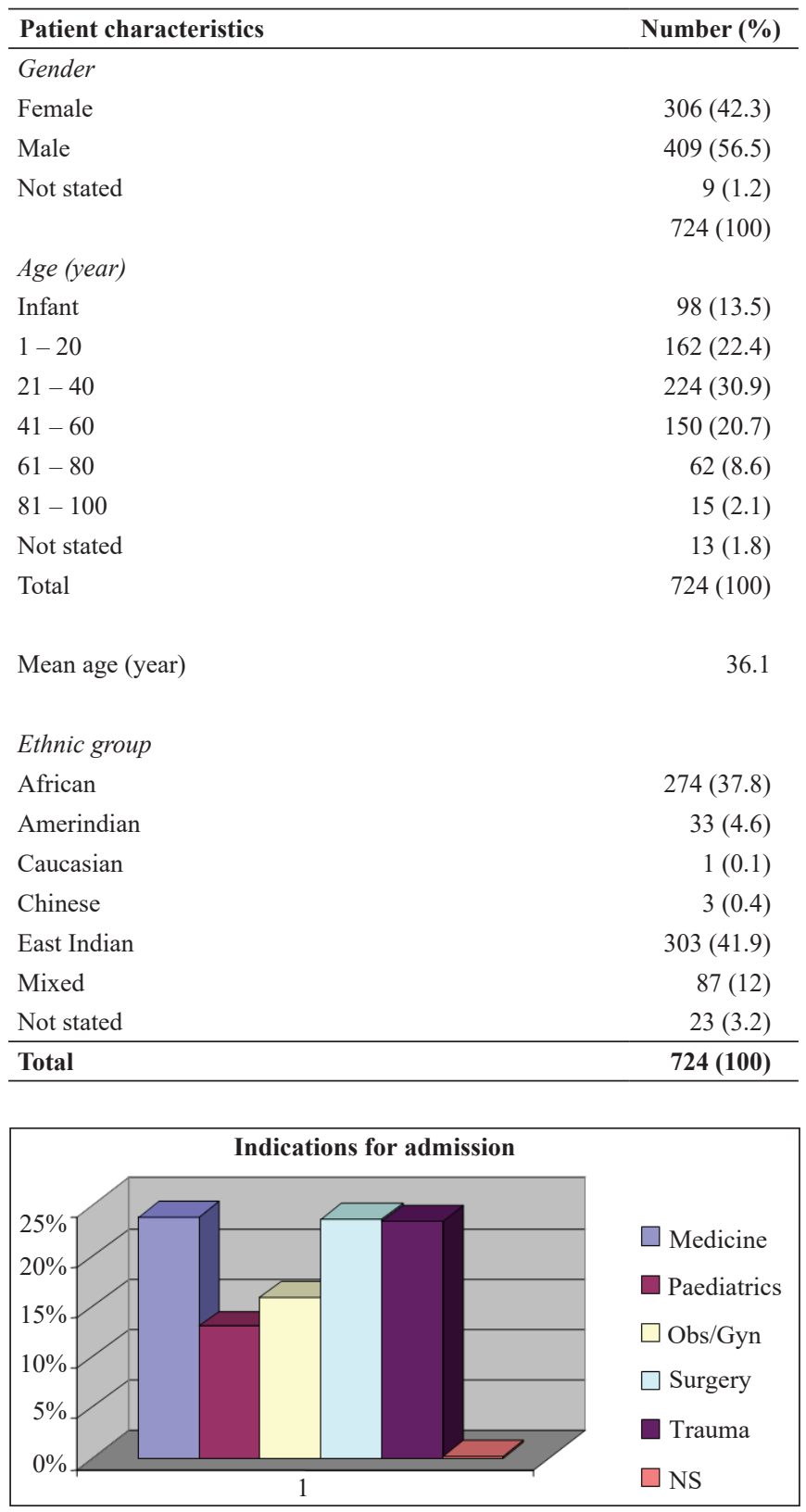

Fig 2: The indications for the intensive care unit admissions. Obs/Gyn: Obstetric and gynaecologic; NS: not stated 
The majority of the patients admitted to the ICU $(60 \%)$ did not have their lungs mechanically ventilated. Of those who were ventilated, $66 \%$ died in the ICU compared to $36 \%$ of those who were not ventilated.

The average length of stay for the study sample was 5.46 days. The patients who were discharged from the ICU had an average longer length of stay than those who died (Table 2). Seventy-nine per cent of the patients were in the ICU for one-week or less and slightly more than half $(52 \%)$ of all the admitted patients stayed for less than 72 hours (Fig. 3).

Table 2: Patients average length of stay

\begin{tabular}{lc}
\hline Average length of stay & Number \\
\hline Discharges & 6.25 \\
Total study population & 5.46 \\
Deceased & 4.6 \\
\hline
\end{tabular}

The proportion of deaths, compared to discharges, was highest amongst the patients in the medical and paediatric groups with $70 \%$ and $66 \%$, respectively. The other groups had a greater proportion of discharges compared to deaths. The obstetrics and gynaecology groups had the greatest proportion of discharges compared to deaths with $88 \%$ of these patients being discharged from the ICU.

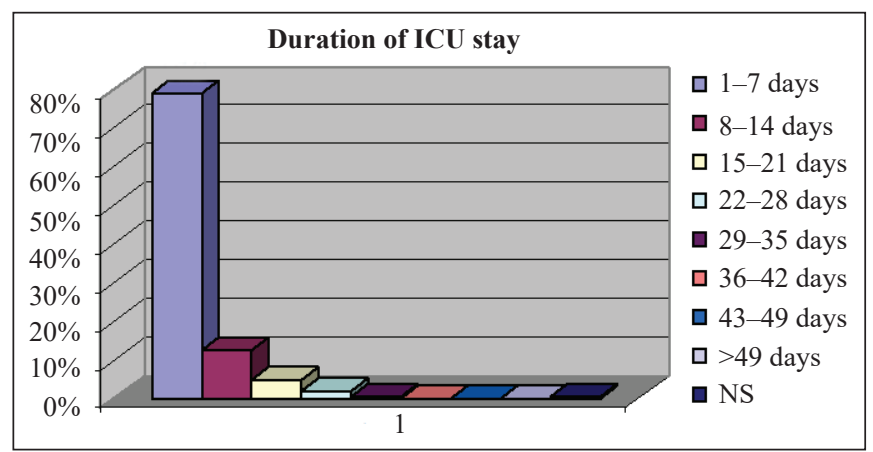

Fig: 3 Length of stay of patients admitted to the intensive care unit.

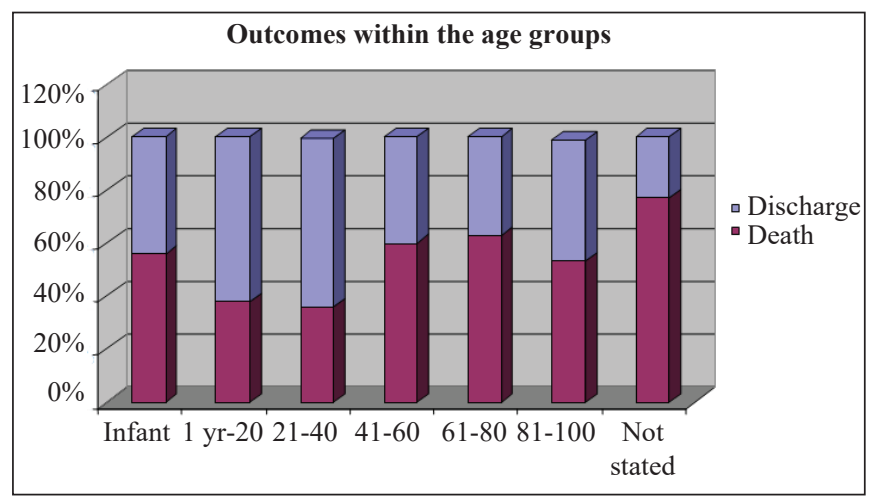

Fig 5: Outcomes between the age groups.
Mortality was lowest in the age groups 1-20 years and 21-40 years and highest in the groups $41-60$ years and $61-80$ years (Fig. 5). Mortality was also lower in females compared to males (Fig. 6).

\section{DISCUSSION}

This retrospective study, reviewed the admissions to the GPHC - ICU for the period January 2008 to December 2009. Unlike the ICU admissions in the developed Western world where the majority of patients are the elderly (2-5), the average age of our patients was only 36.1 years within the age group $21-40$ years being the modal group $(30.9 \%)$. Those over 60 years accounted for only $10.7 \%$ of the admissions. This age distribution reflects the typical age population pyramid of poor developing or emerging countries such as Guyana with high birth rates, high migration rates and low life expectancy. Thirty-six per cent of the population of Guyana is under 15 years of age and more than half of the population $(53 \%)$ is under 25 years of age (6).

A contributory factor to the low mean of the ICU admission age is the fact that our ICU caters for patients from infancy to geriatrics. This is in contrast to many modern ICUs in the developed world where there are

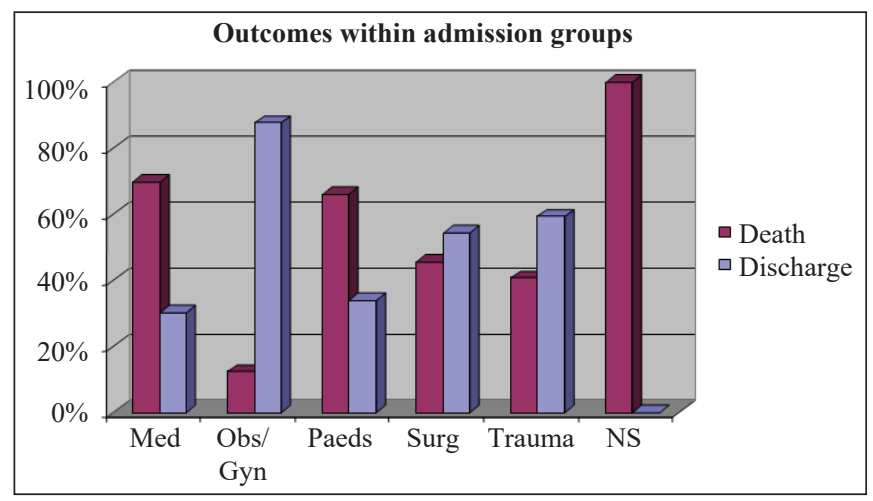

Fig 4: Outcomes of patients based on their indications for admission to the intensive care unit.

Med: Medicine; Obs/Gyn: obstetric and gynaecologic; Paeds: paediatrics; Surg: surgery; NS: non-survivors

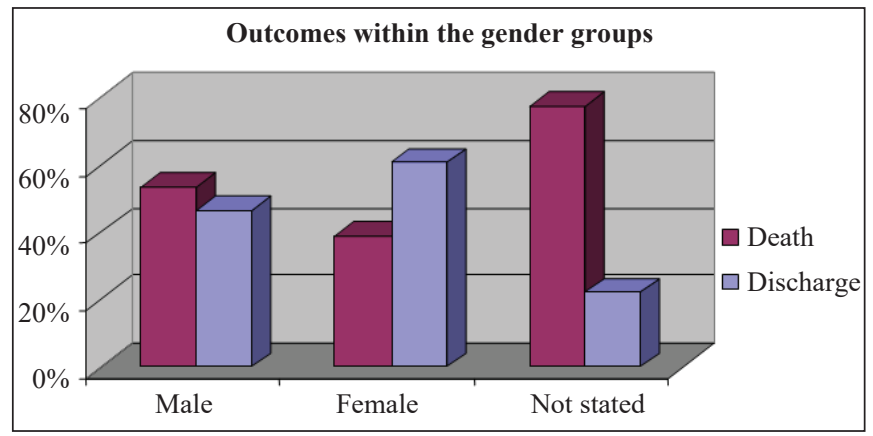

Fig 6: Outcomes between genders. 
separate ICUs for children and for adults. It has been well established that paediatric mortality rates are higher in general ICUs than in dedicated paediatric ICUs (7). The mortality rate in our paediatric age group was relatively high at $66 \%$, second only to the adult medical group with a mortality rate of $70 \%$. Though the paediatric age group range is wide, from one month to 12 years, the majority of our paediatric ICU admissions were infants and the most common indications for admission were respiratory distress/hyaline membrane disease and pneumonia. The combination of a high mortality rate in the paediatric group, with the majority being infants and the specialized skills needed in the care of this group of patients may be the justification for a dedicated PICU in our hospital. Children have their unique challenges and they are probably best cared for in a dedicated PICU with appropriate expertise and equipment. There is currently a Neonatal Intensive Care Unit (NICU) in the hospital.

The fact that the largest group of our ICU patients, almost one-third $(30.9 \%)$, are in the age range between 21 and 40 years, commonly considered the most productive phase of one's life, has implications for the economy and the productivity of the nation. The contributors to the high numbers in this age group are the high cases of trauma especially due to road traffic accidents, interpersonal violence and suicide attempts among males and obstetric complications in females.

Trauma was the most common cause of ICU admission and was mostly due to motor vehicle crashes. The high mortality noted in our patients with significant intracranial trauma is often a combination of several factors such as the severity of the injury, delayed emergency medical services, lack of proper helmets, limited use of seatbelts and lack of appropriate resources. Interestingly, similar findings have been noted in other resource-constrained developing countries in: Africa, Asia, Middle East, and Central and South America (8-16). Also, like in these other ICUs, the preponderance of male patients $(57.6 \%)$ in our ICU is attributable to the higher male involvement in trauma especially motor vehicle crashes and interpersonal violence.

The majority of our ICU admissions (38\%) came from the operating theatres. These included both planned and unplanned cases. This is similar to surveys in other developing world ICUs with reported proportions from 11 to $75 \%$ (14), but is in contrast to the ICUs in many developed countries where the majority of their admissions are medical (2-5). The possible explanations are that our patients tended to present late with advanced pathology and often as emergency cases. The standard of care on the regular wards was also occasionally suboptimal.

Our study indicated that survivors have a longer duration of ICU stay than non-survivors and the majority of our non-survivors expire within 72 hours of admission. This is similar to the large national study from Tanzania and the study from Nigeria $(8,10)$ but in contrast to the National Australian Study that indicated that non-survivors have a longer mean length of stay [LOS] (5).

Obstetric admissions to our ICU were relatively very high (16\%) compared to reports from the western developed world. The most common indications for admission were eclampsia and obstetric haemorrhage. Mortality in this group of patients was relatively low and this is likely due to the fact that the patients are relatively young and they usually have no significant pre-existing co-morbidities (12).

Our medical specialty admissions had the highest mortality. Guyana, like many developing countries, has a high prevalence of infectious diseases. Tuberculosis, viral haemorrhagic fevers, tetanus and malaria, which have been eliminated from most developed countries, provide a worryingly high incidence of new cases. Surprisingly, the disease burden from chronic noncommunicable diseases exceeds that of communicable diseases. Hypertension, diabetes and obesity, further contribute to an emerging epidemic of cardiovascular disorders and end-stage renal failure. This has placed a heavy demand for expensive specialty care relating to dialysis and renal transplant.

Two very common medical conditions in our ICU that are unusual elsewhere are suicide attempts and near drowning. According to the most recent World Health Organisation's report, Guyana has the highest suicide rate in the world, with rates that are four times higher than the global average (17). Ingestion of pesticides and hanging are the common means of suicide in Guyana and male youths are the main victims. The name Guyana comes from the local Amerindian language and means 'The land of many waters' because it is criss-crossed by numerous rivers, streams and creeks (1). Easy accessibility of such bodies of water predisposes male youths to the high incidence of drowning.

The relatively high mortality of our patients, similar to that of other low-resource developing countries, is related to the severity of the illness or injuries and the delayed or late referrals when patients are already in extreme conditions and delay in instituting effective therapies in acutely ill patients because of the poor 
communication and transportation infrastructure and the occasional suboptimal basic resuscitation services. The recent acquisition of many ambulances by the Government manned by trained emergency medical technicians and the greater penalties for traffic-related offences will hopefully improve this situation.

An interesting observation is that irrespective of geographical location, ICU case-mixes and service conditions and delivery are remarkably similar in most of the least developed or low-income countries. Our findings corroborate the extensive review and analysis of intensive care medicines in many developing countries by Dunser et al (14) and also by Towey and Ojara (15) and Baker (16). In summary, the most common indications for ICU admissions are postoperative observation, trauma, obstetric complications and infectious diseases. Intensive care unit mortality rates are quite high and the contributors to the high mortality are very limited resources and delayed presentations.

There are some limitations to our study. The study was retrospective and the survey is a bit dated. Since the completion of the study, a number of developments have taken place in the ICU and the results may not accurately reflect the current events. The biggest challenge was poor documentation and record-keeping. Some charts were missing or misfiled; those available may not have contained all the information needed and the relevant information may not have been legibly recorded. There is a plan for hospital-wide computerisation of all records. There was no standardized diagnostic or disease classification system; so the accuracy of our groupings or classes could not be assured. Also, illness severity scoring was not routinely done; so, comparisons with other ICUs could not be made.

\section{CONCLUSION}

Our ICU provides essential, relevant and often lifesaving care to patients in spite of the various limitations we face. The mortality rate, however, remains relatively high and many of the deaths were potentially preventable by simple public health interventions like immunization, vehicular accident reduction strategies, suicide prevention strategies, better sanitation, greater availability of primary healthcare, prompt basic emergency services and regular availability of essential laboratory services and pharmaceutical supplies. The training of human resources for the ICU as well as improved documentation and record keeping should be a priority.

\section{REFERENCES}

1. Bureau of Statistics, Guyana. Available from: http://www.statisticsguyana.gov.gy. [Cited on May 15, 2015].

2. Halpern NA, Pastores SM. Critical care medicine in the United States 2000-2005: An analysis of bed numbers, occupancy rates, payer mix, and costs. Crit Care Med 2010; 38: 65-71.

3. Sparkes DJ, Smith GB, Prytherch D. Intensive care requirements for an ageing population - a microcosm of problems facing the NHS? Clin Med 2004; 4: 263-6.

4. Wunsch H, Harrison D, Linde-Zwirble W, Angus D, Rowan K. Differences in ICU admissions for the elderly between the United States and the United Kingdom. Critical Care 2006, 10 (Suppl 1): P429 Available online at: http://ccforum.com/content/10/S1/ P429 [cited May 28, 2015].

5. Bagshaw SM, Webb SAR, Delaney A, George C, Pilcher D, Hart GK, Bellomo R. Very old patients admitted to intensive care in Australia and New Zealand: A multicentre cohort analysis. Crit Care 2009; 13: R45. Available online at: http://ccforum.com/content/13/2/R45 [cited May 28, 2015]

6. Guyana Country Statistics. Available from: http://www.statisticsguyana. gov.gy/pubs/Chapter2_Population_Composition.pdf

7. Pearson G, Shann F, Barry P, Vyas J, Thomas D, Powel C et al. Should pediatric intensive care be centralised? Trend versus Victoria. Lancet 1997; 349: 1213-37.

8. Sawe HR, Mfinanga JA, Lidenge SJ, Mpondo BCT, Msangi S, Lugazia $\mathrm{E}$ et al. Disease patterns and clinical outcomes of patients admitted in intensive care units of tertiary referral hospitals of Tanzania. BMC Int Health Hum Rights 2014; 14: 26-33.

9. Gundo R, Lengu ES, Maluwa A, Mtalimanja O, Chipeta D, Kadyaudzu C. An Audit of Admissions to Intensive Care Unit at Kamuzu Central Hospital in Malawi. Open Journal of Nursing 2014; 4: 583-9.

10. Adenekan, AT, Faponle, AF. Trauma Admissions to the ICU of a tertiary hospital in a low resource setting. African Journal of Anaesthesia and Intensive Care 2009; 9: 5-9.

11. Ilori IU, Kalu QN. Intensive care admissions and outcome at the University of Calabar Teaching Hospital, Nigeria. J Crit Care Med, 2012; 27: 105.e1-e4.

12. Tomlison J, Kadyaudzu C, Samuel C, Campbell LP, Charles AG. The burden of surgical disease on critical care services at a tertiary hospital in sub-saharan Africa. Tropical Doctor 2013; 43: 27-29.

13. Mitchell VT, Scarlett MD, Amata AO. Trauma admissions to the ICU of the University Hospital of the West Indies Kingston, Jamaica. Trauma Care 2001; 11: 86-89.

14. Dunser MW, Baelani I, Ganbold L. A review and analysis of intensive care medicine in the least developed countries. Crit Care Med 2006; 34: $1234-42$.

15. Towey RM, Ojara S. Intensive care in the developing world. Anaesthesia 2007; 62: 32-37.

16. Baker T. Critical care in low-income countries. Trop Med Int Health 2009; 14: 143-148.

17. World Health Organization. Preventing suicide: a global imperative. 2014. Available from: http://www.who.int/mental_health/suicide-prevention/world_report_2014/en/ [cited May 30, 2015] 